\title{
EDUCAR PARA EL CUIDADO DE SÍ: UNA REFLEXIÓN DESDE EL PENSAMIENTO SOCRÁTICO
}

\author{
Adriana María Ruiz Gutiérrez* \\ doi:10.11144/Javeriana.uph34-69.ecps
}

\begin{abstract}
RESUMEN
El Fedón de Platón registra las últimas palabras de Sócrates, tan inquietantes como conmovedoras: "Critón, le debemos un gallo a Asclepio. Así que págaselo y no lo descuides”. En oposición a la canónica interpretación nietzscheana según la cual el filósofo ateniente había sufrido la vida como una enfermedad y por ello requería atestiguar su gratitud al dios amo de la curación, Michel Foucault entiende el último decir socrático como una exhortación a no olvidarse, ni descuidarse, sino a ocuparse de la propia vida, descubriendo quiénes somos y cómo podemos ser mejores. La advertencia sobre los riesgos del olvido del yo, el autoolvido, constituye el péndulo de la muerte de Sócrates, desde el principio de la Apología y el Critón hasta el final del Fedón, sintetizando así su actitud ante la vida y la filosofía. Su enseñanza, pues, es esta: "ocupaos de vosotros mismos"; no hay que perderse de vista, retornando siempre ante el peligro del descuido y agradeciendo al dios de la curación, quien alienta al cuidado de sí, consigo y con los otros.
\end{abstract}

Palabras clave: Critón; educación; Michel Foucault; Sócrates; olvido; verdad

* Universidad Pontificia Bolivariana, Medellín, Colombia.

Correo electrónico: adriana.ruiz@upb.edu.co

Para citar este artículo: Ruiz Gutiérrez, A.M. (2017). Educar para el cuidado de sí: una reflexión desde el pensamiento socrático. Universitas Philosophica, 34(69), 143-172. ISSN 0120-5323, ISSN en línea 2346-2426. doi:10.11144/Javeriana.uph34-69.ecps 


\title{
EDUCATION TO SELF-CARE: A REFLECTION ON SOCRATIC THOUGHT
}

\author{
Adriana María Ruiz Gutiérrez
}

\begin{abstract}
Socrates' last words, as reported by Plato in the Phaedo, are as disquieting as touching: "Crito, we owe a rooster to Asclepius. Do pay it. Don't forget". In opposition to the canonical nietzschean interpretation according to which the Athenian philosopher suffered life as an illness and for that reason required to testify his gratitude to the god master of healing, $\mathrm{Mi}$ chel Foucault understands the last Socratic saying as an exhortation not to forget or neglect ourselves, to take care of one's own life, discovering who we are and how we could better ourselves. The warning on the risks of forgetting the self constitutes the pendulum of Socrates' death from the beginning of the Apology and the Crito, to the end of the Phaedo, summarizing his attitude towards life and philosophy. His teaching: "take care of yourselves", we must not pass out of sight, backing away from the danger of carelessness, and thanking the god of healing, who encourages selfcare, both with ourselves and with others.
\end{abstract}

Key words: Crito; education; Michel Foucault; Socrates; forgetfulness; truth 
No hay que considerar lo más importante el vivir, sino el vivir bien.

Platón, Critón, 48b

Sócrates ha llevado una vida tan sabia, tan apartada del cuerpo, que para ella no puede haber mal aqui abajo. Por ende, en el momento en que va morir, en que acepta morir, en que está dichoso de morir, Sócrates jamás dice ni piensa, ni ha dicho ni pensado, que la vida es una enfermedad. Sus últimas palabras, en consecuencia,

son singularmente enigmáticas, toda vez que es preciso admitir que, por un lado, la ofrenda a Asclepio nos sitúa con suma precisión dentro de un ritual que se refiere a la enfermedad y que, por otro, para Sócrates la muerte no puede considerarse en si misma como una curación, porque la vida no puede ser en si misma una enfermedad.

Foucault, El gobierno de si y los de los otros II, p. 117

\section{Introducción}

EN EL FEDÓN DE Platón (427-347 a. C.), que registra la última jornada de Sócrates (470-399 a. C.), sobresalen sus inquietantes palabras de cierre: “[...] Critón, debemos un gallo a Asclepio. Así que págaselo y no lo olvides" (Fedón, 118a). ¿Cómo entender esta confusa expresión del filósofo?, ¿qué indicaciones presta el término olvido, dada su remisión a un gallo y no a la verdad o la sabiduría? La interpretación nietzscheana del Sócrates decadente y pesimista que había sufrido la vida como una enfermedad y que por ello requería atestiguar su gratitud al dios amo de la curación es contrariada por George Dumézil (1898-1986), permitiendo a Michel Foucault (1926-1984) elaborar, a partir de dicha lectura, una novedosa interpretación de la última sentencia socrática, así como de su actitud hacia la vida y la filosofía (Nehamas, 2005, p. 255). De manera análoga a 
Foucault, quien encontró serias dificultades para comprender el término olvido y la apelación a Asclepio, el Esculapio de los latinos, Dumézil se ocupó ampliamente de ambas remisiones, tan desconcertantes como significativas en el pensamiento socrático: Asclepio no presta más que un solo servicio en el mundo de los hombres. No se ocupa sino de enfermos, quienes reciben, a través de un sueño, la receta que los curará si pasan una noche acostados en su santuario (Dumézil, 1989, p. 151). De manera que el sacrificio de un gallo a favor del dios de la curación representa el rito tradicional de los griegos mediante el cual se le agradece la curación efectiva de un alma enferma ${ }^{1}$.

Al respecto, Dumézil (1989, p. 151) y Foucault (2010, p. 111) preguntan al unísono: ¿De qué enfermedad se trata? ¿De qué receta curativa puede tratarse en el caso de Sócrates y sus discípulos? Debemos un gallo: ¿quiénes? ¿Sócrates? ¿Sócrates y Critón? ¿Critón y los demás? La auténtica cuestión reside, pues, en la curación de una antigua enfermedad no tratada, la cual vuelve a la memoria, no puede ser olvidada, y cuyo pago debe ser cancelado por anticipado. De manera análoga a Dumézil, Foucault encuentra una estrecha relación entre el Fedón, el Critón y la Apología, permitiéndole afirmar que el último decir socrático alude, estrictamente, a la enfermedad de Critón, así como a los padecimientos de Cebes y de Simmias, quienes fueron curados en el curso de su diálogo con el maestro ateniense. Critón padecía de una enfermedad que le hacía pensar que para Sócrates era mejor vivir que morir; mientras Cebes y Simmias sufrían la enfermedad que los inducía a creer que, si uno muere, no tiene la certeza de liberar un alma inmortal (Foucault, 2010, p. 124). Al igual que la enfermedad del cuerpo, el alma se degrada cuando tiene ideas que no han sido examinadas y puestas a prueba en función de su verdad. Esta enfermedad no alude en modo alguno a deficiencias mentales que deban ser tratadas mediante procedimientos médicos o psiquiátricos, sino más bien a la corrupción del alma producida por la admisión

1 El gallo representa un símbolo solar, ave de la vigilancia y de la actividad. Esta ave de la mañana se inmolaba a favor de Príapo, dios de la fertilidad, y de Asclepio, dios de la medicina y la curación, para obtener la curación de los enfermos. Durante la Edad Media, el gallo aparecía siempre en la veleta más elevada de las torres y cimborrios de las catedrales, considerándolo como una alegoría de la vigilancia y la resurrección: "[ $t$ ]endencia a la eternidad y cuidado en dar primacía al espíritu, de estar despiertos y saludar al sol (Cristo), aun antes de su salida por Oriente (Iluminación)” (Cirlot, 2014, p. 219). 
de opiniones falsas, esto es, por los decires de todos y de nadie, que configuran una representación distorsionada de sí mismo y de los otros.

Así las cosas, todos, incluyendo el mismo Sócrates, están agradecidos con el dios amo de la curación, puesto que les había curado mediante la atención a sus almas. Pero, ¿en qué sentido la enfermedad los afecta a todos? Citando a Dumézil, Foucault (2010, p. 124) señala que entre Sócrates y sus amigos más cercanos hay un lazo de amistad tal que cuando uno de ellos padece la enfermedad, los otros se conduelen de esta afección, y Sócrates participa de este sentimiento. Además de la empatía frente a sus amigos, Sócrates reconoce su coraje ante la verdad, o lo que es igual, ante sí mismo, los otros y los dioses, evitando incurrir así en la seducción de la fuga propuesta por su amigo Critón. El filósofo no ha olvidado el cuidado de sí mismo, ni de los otros, situando a las almas a prueba en relación con la verdad, incluso la propia, lo que con frecuencia no es bien recibido. Y mientras no esté muerto, el valor de la verdad persistirá en el filósofo ateniense. Por esta razón, el último ritual de curación se hará en nombre de todos, así como de la amistad y la verdad (Apología, 31a). Ahora, la veridicción de las almas conserva un propósito específico en la dramaturgia socrática, puesto que constituye la tarea del maestro, a saber: el cuidado de sí, de sus amigos y de sus conciudadanos, así como un padre, un pastor o un soberano cuidan de su familia, de su rebaño o de sus ciudadanos. Sócrates enseña que lo importante no reside en el dinero, ni en la reputación, sino, en cambio, en el cuidado de sí mismo en relación con la sabiduría, la verdad y el alma (Apología, 29d). Bajo esta perspectiva, Foucault define tal atención como el uso de la propia razón para descubrir quiénes somos y cómo podemos ser mejores.

Durante toda su vida, incluso en su agonía, Sócrates muestra, en efecto, un gran coraje frente aquello que desconoce, próximo e inmediato. Por lo tanto, " $[\mathrm{s}] \mathrm{i}$ cuido de ustedes", dice Foucault, identificando de un modo sutil su voz con la del sabio ateniense, "no es para transmitirles un conocimiento del que ustedes carecen, sino que al darse cuenta de que no saben nada, aprenderán, por lo tanto, a cuidar de sí mismos" (Foucault, 2010, p. 105). Porque el cuidado de sí precede a, o mejor aún, constituye el cuidado del otro. Y Foucault advierte con insistencia en que el asunto del cuidado del yo aparece, aunque de forma sutil, tanto al principio de la Apología como al final del Fedón. En la primera oración de la Apología -obra tan compleja y enigmática como las demás del ciclo socrático-, 
incluyendo, por supuesto, las últimas palabras de Sócrates a favor de Asclepio, Sócrates dice que sus acusadores han hablado de un modo tan articulado que acaso olvidó quién era en realidad: "[n]o sé, atenienses, la sensación que habéis experimentado por las palabras de mis acusadores. Ciertamente, bajo ese efecto, incluso yo mismo he estado a punto de no reconocerme; tan persuasivamente hablan" (Apologia, 17a). Si la oratoria puede generar el olvido del yo, el autoolvido, entonces la parresía, su forma directa y literal de decir la verdad, es un modo de descubrir quién se es, lo que constituye la meta del cuidado de sí y de los otros.

Ahora, ¿qué significa la introducción del olvido de sí y de los otros como una advertencia socrática y, al mismo tiempo, como una enseñanza para el cuidado de sí? La conducción socrática de sus discípulos y amigos versa, pues, sobre los peligros del olvido, el descuido o la desatención de sí mismo y de los otros, lo que genera la mayor de las veces la impostura, o peor todavía, el extrañamiento ante la vida y la filosofía. Este llamado constituye el objetivo y la finalidad de la enseñanza socrática, la cual se distingue de todo contenido de verdad cuya fuerza o brutalidad se dirige a la cabeza del interlocutor, quien no puede más que callarse o sofocarse de furia; por el contrario, la enseñanza socrática alude más bien a la tarea de persuadir al interlocutor sobre la conveniencia de ir desde lo conocido hacia lo desconocido, de lo simple hacia lo complejo, del elemento hacia el conjunto, constituyendo así el progreso propio de la pedagogía. He aquí la inversión de la relación saber-poder fundada en la abstracción de sí y la explicación de otro, tratándose ahora de un juego en virtud del cual el maestro finge no saber, con lo que lleva al discípulo a formular la verdad que no sabía que sabía (Foucault, 2009, p. 72). No se trata en modo alguno de adoctrinar, demostrar o vencer en una discusión, sino, en cambio, de decirse la verdad cara a cara sin artilugios, simulaciones o falsas maneras, atestiguando auténticamente lo que se piensa en lo que se dice. En palabras de Foucault (2009), este enunciado podría calificarse de pacto: "[e]l pacto del sujeto hablante consigo mismo" (p. 81). Y este pacto entraña a su vez una doble manera, a saber: por un lado, el sujeto dice "esta es la verdad", a cuyo contenido se liga; y, por otro, el sujeto expresa "soy quien ha dicho esta verdad" y, por consiguiente, asumo el riesgo de sus efectos.

Desde esta perspectiva de análisis, esta composición recorre la interpretación de Foucault sobre las últimas palabras de Sócrates a Critón, quien retoma la postura dumeziliana, incluyendo las comparaciones con las tragedias de Esquilo 
y Sófocles, además de una serie de textos contenidos en la Apología y el Fedón, especialmente las opiniones de Cebes y Simmias, las cuales confirman la idea según la cual el rito de curación socrática alude, estrictamente, a la superación de las opiniones comúnmente admitidas sin ningún miramiento ni vacilación. Foucault avanza en su interpretación afirmando que el último decir del filósofo ateniense confirma el decir veraz, el coraje ante sí mismo, los otros y los dioses. El filósofo no se ha olvidado de sí mismo, ni de su deber de cuidado ante sí y los otros. Y mientras no esté muerto, el coraje de la verdad persistirá en el filósofo ateniense. Por esta razón, el ritual de curación se hará en nombre de todos, incluyendo al maestro ateniense. Este es, precisamente, el último gesto socrático de amistad y de coraje consigo mismo y con sus amigos. Según Foucault, la solidaridad constituye un elemento definitivo en la comprensión de la dramaturgia contenida en los diálogos platónicos. De modo que todos han sido solidarios en ese ejercicio de la verdad y, por supuesto, en la operación curativa que ha evitado el contagio de todos; por ello es que todos deben agradecer a Asclepio.

Este escrito complementa el trazo foucaultiano, señalando que las palabras de cierre del filósofo ateniense aluden a una educación que no solo advierte sobre los peligros del olvido de sí mismo, sino también del reencuentro consigo mismo y con los otros. Aquí residen las últimas palabras de Sócrates o, más bien, su última voluntad: "ocupaos de vosotros mismos", esto es, de echarse de menos y retroceder ante el riesgo del descuido. Y así como Sócrates habla a Critón, Cebes, Simias, incluso a Foucault, asimismo Dioniso exhorta a Ariadna ante su pérdida y, por lo tanto, ante su reinvención. La razón de esto es que la educación hace posible el descubrimiento de sí, la invención de sí mismo mediante el razonamiento claro y el decir veraz. El enigma del laberinto que conduce al conocimiento resulta análogo al misterio de la vida, incluyendo el decir de los dioses, que exige, más allá de los artificios creados por la habilidad y la astucia del lenguaje, el valor ante la verdad de sí y de los otros. Dar vuelta al mundo inauténtico, la impostura y la servidumbre constituye la enseñanza de Sócrates, quien se esforzó en la búsqueda intensa del saber que atraviesa la mera apariencia, con lo que convierte al hombre en otro gracias al descubrimiento de sus propias fuerzas. 


\section{2. "Sócrates. -Critón, debemos un gallo a Asclepio"}

Sócrates AGRADECE AL Dios de la curación por haberlo librado de un mal presente. No se trata de la vejez ni de las tribulaciones del cuerpo en virtud de la madurez - puesto que Asclepio es un técnico, no cura más que las indisposiciones actuales y declaradas-, sino más bien de otra enfermedad cuyo origen reside en el alma. A diferencia de F. W. Nietzsche (1844-1900), quien acusó a Sócrates de sugerir que la muerte es el remedio contra la vida misma, Dumézil advierte la concepción socrática de la vida entendida como un tiempo de pesares y de pruebas y también de dichas y de ocasiones, pero en ningún caso como un estado de enfermedad. De ahí que el gallo ofrecido a Asclepio no indica el tránsito gozoso de la enfermedad vital a la salud fúnebre, sino, en cambio, el cuidado de la vida misma y de los otros. Basta observar la actitud socrática en los últimos diálogos - Apología, Critón, Fedón- para advertir la presencia de un hombre tranquilo y, en ningún caso, enfermo, quien se niega a dramatizar ante sus amigos contrariados cualquier gesto o palabra ante el encierro y la cicuta; al contrario, Sócrates come, bebe y departe en amables conversaciones (Dumézil, 1989, p. 154)². Con extraordinaria delicadeza, Dumézil corrige la idea según la cual la vida socrática constituye un estado prolongado de padecimiento, anotando en cambio que apunta a "[...] un gimnasio moral, más bien, donde el sabio se torna dueño de los músculos de su alma y que abandona luego sin pena”. Y seguidamente agrega: "[n]o, este mundo no era para él dubkha, pura 'desdicha', ni la muerte, ni una curación. Toda su enseñanza, lejos de desprender a los jóvenes de la vida, los ponía en condiciones de vivirla de veras" (Dumézil, 1989, p. 140).

Vivir implica ejercitar el alma, esto es, el ver y el saber libre de errores y vacilaciones. Por esta razón, Sócrates encomienda a su amigo Critón celebrar un sacrificio a favor del dios de la curación, enseñándole así que la opinión errónea es para el alma lo que la enfermedad es para el cuerpo. Al respecto, es preciso releer el Critón o del deber del siguiente modo: Critón entra a la prisión en el alba y

2 Critón, incluso, manifiesta su sorpresa ante la serena reacción del filósofo: “[e]n esta situación tampoco habría querido yo mismo estar en tal desvelo y sufrimiento, pero hace rato que me admiro viendo qué suavemente duermes, y a intención ni te desperté para que pasaras el tiempo lo más agradablemente. Muchas veces, ya antes durante toda tu vida, te consideré feliz por tu carácter, pero mucho más en la presente desgracia, al ver qué fácil y apaciblemente la llevas" (Critón, 43b). 
aconsejando a Sócrates, manifiesta: "Hazme caso y sálvate [...], muchos que no nos conocen bien a ti y a mí creerán que, habiendo podido yo salvarte, si hubiera querido gastar dinero, te he abandonado" (Critón, 44b). Y seguidamente agrega: "¿[h]ay reputación más vergonzosa que la de parecer que se tiene en más al dinero que a los amigos? Porque la mayoría no llegará a convencerse de que tú mismo no quisiste salir de aquî" (Critón, 44c). A lo que Sócrates responde: "[p]ero ¿̨por qué damos tanta importancia, mi buen Critón, a la opinión de la mayoría? Pues los más capaces, de los que sí vale la pena preocuparse, considerarán que esto ha sucedido como en realidad suceda" (Critón, 44c). La pequeña conspiración ha reunido el dinero que servirá para la fuga de Sócrates: una vez compradas las complacencias de los delatores, los guardias y el tribunal, Sócrates podrá huir de la prisión, llegando hasta Tesalia, donde los amigos de Critón, Simias y Cebes, lo recibirán como el mejor de los huéspedes. Todas las objeciones están previstas: "Critón. - [...] no es mucho el dinero que quieren recibir algunos para salvarte y sacarte de aquí. Además, ¿no ves qué baratos están estos sicofantes y que no sería necesario gastar mucho dinero en ellos?" (Critón, 44e).

Ante la injusticia de la acusación y la sentencia contra Sócrates, esta operación resulta supuestamente incuestionable, ya que el condenado posee tanto derecho como deber de sustraerse a la condena, ora para cuidar de sus hijos y discípulos, ora para enseñar a la humanidad. Aún más, Critón exhorta a Sócrates de un modo enfático a aceptar la propuesta, ya que lo contrario significaría una traición a sí mismo, a sus hijos y a sus amigos: "[t]ampoco me parece justo que intentes traicionarte a ti mismo". Y agrega: "[m]e parece a mí que traicionas también a tus hijos; cuando te es posible criarlos y educarlos, los abandonas y te vas [...]. Me parece que tú eliges lo más cómodo" (Critón, 45d). Sin embargo, Sócrates rehúsa la propuesta con el mismo ímpetu:

Si no somos capaces de decir nada mejor en el momento presente, sabes bien que ni voy a estar de acuerdo contigo, ni aunque la fuerza de la mayoría nos asuste como a niños con más espantajos que los de ahora que nos envía prisiones, muerte y privaciones. [...] Veamos, por lo pronto, si recogemos la idea que tú expresabas acerca de las opiniones de los hombres, a saber, si hemos tenido razón o no al decir siempre que deben tenerse en cuenta las opiniones y otras no (Critón, 46c). 
De manera que la opinión de los muchos, los ignorantes, importa poco. En palabras de Sócrates, solo la opinión de los sabios cuenta para la salud del cuerpo y el alma. Porque la enfermedad que corrompe el cuerpo es, pues, hermana gemela de la opinión falsa que corrompe el alma:

Sócrates. -Luego, querido amigo, no debemos preocuparnos mucho de lo que nos vaya a decir la mayoría, sino de lo que diga el que entiende sobre las cosas justas e injustas, aunque sea uno solo, y de lo que la verdad misma diga. Así que, en primer término, no fue acertada tu propuesta de que debemos preocuparnos de la opinión de la mayoría acerca de lo justo, lo bello y lo bueno y sus contrarios. Pero podría decir alguien que los más son capaces de condenarnos a muerte (Critón, 48a).

Así las cosas, la enfermedad corporal no puede ser tratada por la multitud, sino por el hombre de Asclepio, el único especialista. La opinión errónea, que procede las más de las veces de una sumisión irreflexiva al sentir de los muchos, no puede ser corregida más que por un examen esclarecido, filosófico, fundado en principios ciertos. Aquí se trata verdaderamente de restablecer el equilibrio del ánimo, de tornarlo phrónimos, o en palabras más exactas, sano, sabio, regulado; en oposición al enfermo del espíritu, áphrōn, quien padece de la opinión errónea como una enfermedad. He aquí la tarea del filósofo, la cual ha sido encomendada numerosas veces por el dios de Delfos y que su demonio le ha recordado a menudo a Sócrates, esto es, curar o, mejor, transformar a los aphrones en phrónimoi (Dumézil, 1989, pp. 160-162). De manera que la curación que le vale un gallo a Asclepio es la de Critón mismo:

Desde una opinión especiosa pero insana, Sócrates, médico del pensamiento, conduce a su viejo amigo hasta la opinión sana; olvidando la multitud y sus faltas evidencias. Seguidamente, y después de escuchar al maestro, Critón, convencido, se pone de parte de las Leyes; está sanado (Dumézil, 1989, p. 161).

Las referencias a la enfermedad y a la cura del alma no aluden únicamente, como podría entenderse en apariencia, a la persistencia y a la superación de la percepción equivocada; más bien, aluden a la toma de una posición urgente y definitiva frente a sí mismo y a los otros. Al respecto, y de forma inminente, Critón apremia a Sócrates: 
Pero toma una decisión; por más que ni siquiera es esta la hora de decidir, sino la de tenerlo decidido. No hay más que una decisión; en efecto, la próxima noche tiene que estar todo realizado. Si esperamos más, ya no es posible ni realizable (Critón, 46a).

Sócrates, a su vez, responde: "[a]bandona tu proyecto y actuemos, en el sentido que digo, ya que es en este sentido en el que nos guía el dios" (Critón, 54d). Con una sutil y extraordinaria belleza, Dumézil (1989, p. 165) recuerda las similitudes de este diálogo entre Sócrates y Critón con la pieza trágica de Sófocles (498-406 a. C.), Antígona: Tiresias -incluso Hemón- es a Creonte lo que Sócrates es a Critón. Basta recordar, en este punto, que esta tragedia alude, específicamente, a la razón práctica y al modo en que los personajes organizan y hacen el mundo. A diferencia de un número importante de obras similares, Antígona se encuentra colmada de expresiones referidas al conocimiento sobre las cosas. Comienza con la pregunta “¿Sabes?”, relativa a una crisis práctica, y con una afirmación sobre el modo correcto de ver las cosas, para concluir con la idea según la cual la prudencia es el elemento más importante del buen vivir humano ${ }^{3}$ (Nussbaum, 2004, p. 91). En efecto, Creonte ha tomado la más grave y apremiante decisión durante su gobierno: ha prohibido sepultar a su sobrino, Polinices, quien osó tomar las armas contra Tebas, anunciando, además, que todo aquel que infringiera su decisión sería condenado a muerte. Antígona, sobrina de aquél y hermana del insepulto, ha transgredido la legítima sentencia en nombre de una ley más antigua que ordena restituir a la tierra todo aquello que ha brotado de la misma:

Antígona. -No fue Zeus el que los ha mandado publicar, ni la justicia que vive con los dioses de abajo la que fijó tales leyes para los hombres. [...] No pensaba que tus proclamas tuvieran tanto poder como para que un mortal

3 Aunque el lector experimenta una mayor empatía por Antígona debido a su defensa de la familia, tanto ella como Creonte adolecen de una perspectiva amplia sobre las cosas, precipitándose a la muerte. En este sentido, en su obra La muerte de Antígona. La tragedia de Creonte, Jean Bollack (1999) afirma que "el exceso hace que la terquedad de Antígona resplandezca a la luz. El derecho mítico de ultratumba se hace valer; hubiera podido no hacerlo, como Creonte hubiera podido sin duda no mantener su condena hasta el final. Antígona no se hubiera aferrado a la ley de Zeus, que en tal caso no hubiera tenido ya nada de una necesidad. Hay algo forzado, incluso desquiciado en todos esos procedimientos. El estado que la tragedia proyecta parece en segundo grado, de modo casi experimental o suplementario, como un orden terrible, terrible pero forzado. Creonte no ha podido salir de su lógica. Fracasa, lastimosamente debe pagar" (p. 77). 
pudiera transgredir las leyes no escritas e inquebrantables de los dioses. Estas no son leyes de hoy ni de ayer, sino de siempre (Antígona, 450-455).

Y así como Antígona se obstinó en la transgresión respecto al tirano, marchando hacia la muerte, Creonte ordenó la ejecución de la mujer en nombre de su poder: "[l]as voluntades en exceso obstinadas son las que primero caen, y que es el más fuerte hierro, templado al fuego y muy duro, el que más veces podrás ver que se rompe y se hace añicos" (Antígona, 475). Y así como Sócrates se dirige a Critón a fin de hacerlo más sensato, Hemón se dirige a su padre, Creonte, exhortándolo a hablar y a escuchar a los que saben con moderación:

Hemón. -Padre, los dioses han hecho engendrar la razón en los hombres como el mayor de todos los bienes que existen. Que no hablas tú estas palabras con razón, ni sería yo capaz de decirlo ni sabría. Sin embargo, podría suceder que también en otro aspecto tuviera yo razón. A ti no te corresponde cuidar de todo cuanto alguien dice, hace o puede censurar. [...] No mantengas en ti mismo solo un punto de vista: el de que lo que tú dices y nada más es lo que está bien. Pues los que creen que únicamente ellos son sensatos o que poseen una lengua o una inteligencia cual ningún otro, estos, cuando quedan al descubierto, se muestran vacíos. Pero nada tiene de vergonzoso que un hombre, aunque sea sabio, aprenda mucho y no se obstine en demasía. Puedes ver a lo largo del lecho de las torrenteras que, cuantos árboles ceden, conservan sus ramas, mientras que los que ofrecen resistencia son destrozados desde las raíces. De la misma manera el que tensa fuertemente las escotas de una nave sin aflojar nada, después de hacerla volcar, navega el resto del tiempo con la cubierta invertida. Así que haz ceder tu cólera y consiente en cambiar. Y si tengo algo de razón -aunque sea más joven-, afirmo que es preferible con mucho que el hombre esté por naturaleza completamente lleno de sabiduría. Pero, si no lo está -pues no suele inclinarse la balanza a este lado-, es bueno también que aprenda de los que hablan con moderación.

Corifeo. -Se ha marchado, rey, presuroso a causa de la cólera. Un corazón que a esa edad sufre es terrible.

Creonte. -La llevaré allí donde la huella de los hombres esté ausente y la ocultaré viva en una pétrea caverna, ofreciéndole el alimento justo, para que sirva de expiación sin que la ciudad entera quede contaminada. Así, si suplica a Hades -único de los dioses a quien venera-, alcanzará el no morir, o se 
dará cuenta, por lo menos en ese momento, que es trabajo inútil ser respetuoso con los asuntos del Hades (Antígona, 685-720; 765; 775).

Y al igual que Hemón, el advino Tiresias exhorta al rey:

Tiresias. -Recapacita, pues, hijo, ya que el equivocarse es común para todos los hombres, pero, después que ha sucedido, no es hombre irreflexivo ni desdichado aquel que, caído en el mal, pone remedio y no se muestra inflexible. La obstinación, ciertamente, incurre en insensatez. Por tenerte consideración te doy buenos consejos. Muy grato es aprender de quien habla con razón, si ha de reportar provecho.

Tiresias. -Príncipe de Tebas, por un camino común hemos venido dos que ven por uno solo. Pues para los ciegos el camino es posible gracias al guía.

Tiresias. - ¡Ay! ¿Acaso sabe alguien, ha considerado...?

Creonte. -¿Qué cosa? ¿A qué te refieres tan común para todos?

Tiresias. -¿Que la mejor de las posesiones es la prudencia?

Creonte. -Tanto como, en mi opinión, el no razonar es el mayor perjuicio.

Tiresias. -Tú, no obstante, estás lleno de este mal (Antígona, 1025-1050).

Y en la pieza trágica, este error en el juicio conduce, así como en la historia del pensamiento filosófico y en la vida misma, a las más severas consecuencias, porque la falsa opinión induce, sin excepción, a decisiones culpables: "Criado. -El deber nos empuja a obrar en el presente”. De esta manera, el coro insta a sus espectadores a ser prudentes y discretos: "[1] as palabras arrogantes de los que se jactan en exceso, tras devolverles en pago grandes golpes, les enseñan en la vejez la cordura” (Antígona 1350). Al igual que Critón ante Sócrates, Creonte se precipita a modificar su posición ante el vidente Tiresias, aunque por miedo y, en modo alguno, por convicción. No obstante, la conversión sucede tardíamente, ya que los resultados de la trágica decisión se han producido de manera irreversible e irreparable: Hemón y Eurídice han hendido el puñal sobre sus cuerpos y Antígona se ha colgado en el subterráneo. En el mismo sentido, Dumézil rememora el Agamenón de Esquilo (525 a. C. 456 a. C.), en el que el Atrida, quien debió sacrificar a su hija Ifigenia para que los vientos le condujeran a Troya, ciudad culpable del rapto de Helena, mujer de su hermano Menelao, y obtener la victoria con el ejército que tenía a su mando. Sin embargo, Agamenón se arrepiente de la decisión e intenta contrariar el mandato de los dioses: "[g]rave destino lleva el no obedecer, pero 
grave también si doy muerte a mi hija -la alegría de mi casa- y mancho mis manos de padre con el chorro de sangre al degollar a la doncella junto al altar". Y agrega: “¿[q]ué alternativa está libre de males?” (Agamenón, 205-210).

Para ayudar a una guerra vengadora por el rapto de su mujer y en beneficio de la escuadra, Menelao habla en nombre de los jefes, ávidos de combatir, y persuade al inmolador de su propia hija, quien le responde, sin embargo, lo siguiente: "Grecia está enferma contigo, por voluntad de algún dios". De este modo, se distingue entre el "pensar bien", propio del espíritu, y el juicio desordenado, que es su enfermedad (Dumézil,1989, p. 167). Naturalmente, la enfermedad no se refiere a un estado de locura, sino a la percepción errada de la realidad, la cual se manifiesta en discursos y, sobre todo, en acciones. Con admirable precisión, Dumézil (1989) señala: “[d] e manera que la enfermedad y la curación son intelectuales, lo que está en juego, el resultado, no lo es” (p. 167). En efecto, las ideas generan los actos y, con estos, las consecuencias reales en la vida de cada hombre. A propósito, Dumézil retoma la literatura clásica para advertir sobre las graves consecuencias generadas en virtud de las ideas erradas. En este punto, el pensador se remite al diálogo entre Aquiles y Ulises, quien intenta persuadir a aquél para que reciba a satisfacción la reparación ofrecida por Agamenón, quien había arrebatado la joven Briseida de la tienda de Aquiles, con el propósito de retomar la batalla en la que los griegos estaban a punto de sucumbir. No obstante, y pese a los ruegos, el héroe encolerizado, persiste en su posición inamovible e insensible, negándose a retomar la guerra y el ejército: "Aquiles tiene en su pecho un corazón feroz y soberbio" (Iliada, 624). Bajo esta perspectiva, el paralelo entre Aquiles y Sócrates no admite contradicción: uno y otro han sido constreñidos por quien detenta el poder y, sin embargo, la reacción de ambos hombres revela una profunda contradicción. Mientras el héroe encolerizado decide abandonar el ejército, al cual lo liga un deber de solidaridad, el filósofo griego decide partir hacia los campos Elíseos y, en modo alguno, abandonar la ciudad ingrata e injusta que lo ha acusado de impiedad. De este modo, se comprenden las palabras de Sócrates cuando relata su sueño a Critón: "Me pareció que una mujer bella, de buen aspecto, que llevaba blancos vestidos se acercó a mí, me llamó y me dijo: Sócrates, al tercer día llegarás a la fértil Ptía" (Critón, 44b). Aquí el sueño se presenta al modo de una revelación, el que se superpone al diálogo entre Sócrates y Critón, confirmando la decisión del filósofo y debilitando la resistencia de su amigo: 
En suma, la partida se desdobla, ocupa dos pisos del gran casino que es el mundo. Ya ha sido jugada, rápida y silenciosa, en lo invisible, que no se comunica con nuestro mundo más que por los oráculos, los signos, los sueños premonitorios; y va a jugarse todavía, verbosa e inútil, en la tierra, en la cárcel, entre los hombres (Dumézil, 1989, p. 174).

El mandato divino es fielmente obedecido por el pensador ateniense, porque encuentra la conformidad del mismo con su vida y su actitud ante la filosofía. Naturalmente, el dios que hace aparición en el mundo onírico socrático es el propio Asclepio, quien interviene desde el inicio de la conversación entre ambos amigos y, por supuesto, con anterioridad a las palabras de Critón, quien solicita al filósofo rehusar la pena establecida por los atenienses.

En toda la tierra griega, quien desea conocer el remedio para su enfermedad debe dormir en el santuario de Asclepio, esperando que un sueño le dicte la conducta, el remedio apropiado: “[c]autivo, encadenado, Sócrates evidentemente no ha estado en condiciones de ir a dormir y a soñar al asclepeion: de modo que ha sido Asclepio quien ha acudido a él”. Y, Dumézil (1989) añade: “[j]ustamente en el momento en que Sócrates iba a tener que afrontar la última 'crisis de falso buen sentido' de su amigo y, al mismo tiempo, que curarlo” (p. 175). Ahora, ¿qué razón posee el amo del sueño para pasar por Sócrates, indicándole a Critón el remedio para la enfermedad, por la que el enfermo no se sabía afectado? Con la misma sutileza que cobra la interpretación dumeziliana sobre el Critón, la respuesta estriba en considerar la amistad como la virtud por antonomasia del maestro, quien enseña a partir de la unidad y la solidaridad, comprometiendo al otro en el saber auténtico de sí mismo o, en palabras más breves, solicitando al otro que no se olvide de sí. Además, Sócrates es el hombre justo, es decir, el hombre que está en relación con otros hombres y, especialmente, con sus amigos enfermos: "Critón, como hubiera dicho la marquesa, está mal de Sócrates, y Sócrates, doblemente vinculado a Critón por la amistad y por esta especie de imperiosa simbiosis, no puede menos que sentirse a disgusto" (Dumézil, 1989, p. 176). La razón de ello es que enfermedad de Critón tiene manifestaciones repetidas: la elaboración de los preparativos del plan de fuga y de soborno, las cuales alcanzan a turbar la serenidad del filósofo. Sin embargo, al justificar su propia decisión, el maestro es el medio de curación de su amigo, puesto que el dios de la curación no sustituye en ningún caso la voluntad y la refutación socrática. 
Las palabras de Sócrates son, pues, una larga y profunda meditación en voz alta que le permiten recordar quien ha sido y quién será ante él mismo, ante sus amigos y ante la filosofía. Por supuesto, esta reflexión ha sido solo un pretexto frente a aquel que habla en nombre de otros discípulos, incluyendo a Platón quien por primera vez habla en el Fedón, sollozante ante la muerte inminente de su maestro- ya que debió hacerla más de una vez, consigo mismo y a solas. Esta manera socrática de advertir el "mal juicio" de sus amigos revela que todo hombre está en capacidad de padecer esta enfermedad del espíritu y que, por tanto, se le debe un gallo al dios de la curación, quien prescribe en la soledad del espíritu el remedio para la enfermedad. El silencio aunado a la amistad y al amor a la filosofía hacen proferir las últimas palabras socráticas: "Critón, debemos un gallo a Asclepio. Así que págaselo y no lo olvides” (Fedón, 118a).

\section{Sócrates y la verdad de si}

En EL CORAJE DE LA VERDAD. El gobierno de sí y los otros II. Curso en el Collège de France (1983-1984), clase del 15 de febrero de 1984, Foucault (2010) se ocupa igualmente de las últimas palabras de Sócrates, el filósofo deudor del dios de la curación, quien dirigiéndose a su amigo Critón y, a decir verdad, a todos sus amigos, los exhorta a pagar la deuda: "[n]o lo olviden, no lo descuiden" (p. 88). En palabras del filósofo francés (2010), el Fedón y su inquietante cierre constituye "[u]n texto que jamás ha explicado o interpretado ninguno de los historiadores de la filosofía o los comentaristas que, desde hace dos mil años, se han consagrado [al asunto]" (p. 88). E inmediatamente agrega: "Dumézil ha analizado y cuya solución, creo, ha encontrado, en el libro que les recomendé leer la vez pasada” (Foucault, 2010, p. 88). En este punto, Foucault se refiere a las reflexiones dumezilianas contenidas en Nostradamus. Sócrates, las cuales le permiten realizar una interpretación radicalmente renovada del diálogo, así como de la última frase socrática, destacando tanto el decir veraz del filósofo, como los riesgos de olvidarse de sí mismo. Según Foucault, la relación entre "la verdad de sí” y "el olvido de sí" constituye el vector fundamental de su discusión acerca del exilio, la salvación y, finalmente, la muerte del maestro: “[...] desde el inicio (estuvieron a punto de hacerme olvidar de mí mismo) hasta el 'no me olvidéis' que son las últimas palabras de Sócrates -me amelésete: no descuidéis, no olvidéis-” (Foucault, 2010, p. 89). 
Foucault retoma entonces la tesis de Dumézil, según la cual únicamente se debe prestar atención a las opiniones correctas, con independencia de su aceptación por parte de la mayoría, porque de lo contrario se daña el alma: "[y] si, como todo el mundo sabe, no vale la pena vivir con un cuerpo corrupto, mucho menos vale la pena vivir con un alma corrompida" (Foucault, 2010, p. 89). Por ello, es preciso desoír los dichos de tantos y de nadie, escuchando la propia voz y mirando la verdad con los propios ojos en lugar de las falsas opiniones (Foucault, 2010, p. 89; Nehamas, 2005, p. 244).

Ahora, y con admirable agudeza, Foucault entrelaza la Apología (proceso), el Critón (castigo), y el Fedón (muerte), esto es, el ciclo de la muerte socrática, para advertir que el último decir del filósofo corresponde a la enfermedad de la que Critón fue curado mientras dialogaba con su maestro, a saber: la falsa creencia, engendrada por su fe en la opinión de los muchos. Por esta razón, ambos agradecieron al dios de la curación, Asclepio, porque Critón reconoció que el sometimiento a las leyes era una condición sine qua non de la política ateniense, pese a la injusta acusación contra Sócrates y a su inminente fallecimiento (de Romilly, 2004, p. 92). En la Apología, Sócrates insiste en que sus acusadores mienten, mientras él dice la verdad, lo que se entiende sin mayores dificultades teóricas. No obstante, la seguida afirmación del filósofo sí genera una profunda inquietud: "los que mienten son mis adversarios, que son hábiles para hablar, pero lo son a tal punto que logran incluso hacerme casi olvidar lo que soy. Por ellos, he perdido casi la memoria de mí mismo" (Apología, 17a). Así las cosas, el hablar de otros, la habilidad de los adversarios, produce un peligro para el propio filósofo, exponiéndolo a la extrema situación de olvidarse de sí mismo (Foucault, 2010, p. 89). De manera que la forma inversa de esta proposición genera una consecuencia distinta: $s i$ la habilidad para hablar provoca el olvido de sí mismo, la sencillez del hablar, la palabra directamente veraz, la palabra, por tanto, de la parresía, nos conducirá a la verdad de nosotros mismos: "Sócrates. -Vosotros vais a oír de mí toda la verdad; no oiréis bellas frases, como las de estos, adornadas cuidadosamente con expresiones y vocablos" (Apología, 17a; Foucault, 2010, p. 89). Sócrates alude a la figura del parresiasta político que -a pesar de los peligros, las amenazas y las contradicciones- acepta decir la verdad por interés de la ciudad. O lo que es lo mismo, cumple su misión cuidando de sus conciudadanos como un padre o un hermano mayor, quien enseña a los suyos que lo importante no es 
el dinero o la reputación, sino más bien el cuidado de sí mismos. Y el cuidado alude, justamente, al uso de la propia razón para descubrir quién se es y puede llegarse a ser (Nehamas, 2005, p. 256).

La parresía socrática no alude a la forma política, al decir la verdad públicamente y a dar consejos a los ciudadanos. Su daimón, esa voz que se hace oír en él a modo de una expresión tan íntima y familiar, le advierte sobre aquello que no debe hacer, ni habrá de hacer; le desvía de hacer política. Asimismo, la voz lo disuade de cuidar a los ciudadanos en la forma de la política. En palabras de Foucault, la explicación socrática es tan reveladora como alarmante: la parresía política, en general, y la democrática, en particular, imposibilitan actuar verazmente, íntegramente, hasta las últimas consecuencias, generando un grave peligro para todo aquel que exponga la verdad en nombre de la justicia y la legalidad: "Sócrates. -Si tiempo atrás me hubiera dedicado a la política, estaría muerto desde hace mucho" (Apología, 32c). Se sabe, pues, que la parresía es peligrosa y, sin embargo, "Sócrates tuvo el coraje de afrontar sus riesgos. Tuvo el coraje de tomar la palabra, tuvo el coraje de dar una opinión adversa frente a una asamblea que procuraba hacerlo callar, perseguirlo y eventualmente castigarlo" (Foucault, 2010, p. 94). He aquí la aparente contradicción: en principio, Sócrates se niega decir la verdad en público, porque de hacerlo sabe con certeza el riesgo, la muerte, pero asume, en cambio, distintos peligros a lo largo de su vida para hacer valer la verdad y la justicia, tanto en la democracia como en la oligarquía, hasta admitir incluso morir. Desde esta perspectiva, Foucault señala que la renuncia socrática a la política no obedece en ningún caso al miedo a la muerte, sino a un sentido de propósito; de hacerlo habría muerto, privándose así de realizar su misión: ser útil a sí mismo y a sus conciudadanos. En palabras más precisas:

La razón por la cual Sócrates no ha querido decir la verdad bajo la forma de la veridicción política no es el miedo a la muerte, no es la relación personal con su propia muerte. No es esa relación personal, sino cierta relación de utilidad, cierta relación consigo mismo y con los atenienses, esa relación útil, positiva y benéfica, la razón por la cual la amenaza que los sistemas políticos imponen a la verdad le ha impedido decir esa verdad en la forma política. A través de un signo negativo y de su interpelación, la voz demónica le ha recomendado guardarse de morir. Y no porque el morir fuera un mal a evitar, sino porque, muriendo, Sócrates no habría podido hacer nada positivo (Foucault, 2010, p. 95). 
Los sistemas políticos amenazan la verdad, la impiden mediante toda forma de negación, incluyendo la más radical: la muerte. En este sentido, Foucault comprende el daimón de Sócrates como una suerte de protección contra los riesgos inútiles de la política en aras de realizar responsablemente la tarea positiva que le había sido asignada. Ahora, equé es lo provechoso para Sócrates y los atenienses? Sin duda, cierta relación con los otros y consigo mismo, tan preciosa, útil y benéfica, como la amistad misma, puesto que permite recordarle al otro su relación consigo mismo en medio de las falsas opiniones comunes que en cada ocasión le hacen olvidar la verdad sobre sí. Ahora, Foucault (2010) pregunta: "¿Cuál es esa otra práctica del decir veraz cuya diferencia esencial, fundamental, fundacional con respecto al decir veraz político marca la voz divina?” (p. 96). La veridicción socrática transita por tres relaciones fundamentales, a saber: en primer momento, la relación entre el saber y el poder mediada por los dioses, especialmente por Apolo y la profecía. Querefonte, el amigo de Sócrates, interroga al dios de Delfos sobre quién es el griego más sabio y este contesta que nadie es más sabio que aquél. Sin embargo, y contrariamente a la apariencia, la respuesta es tan enigmática como desconcertante para Sócrates, quien intenta descifrarla: "Sócrates. -¿Qué dice realmente el dios y qué dice el enigma? ¿Qué es lo que realmente dice al afirmar que yo soy muy sabio? Sin duda, no miente, no le es lícito. Y durante mucho tiempo estuve yo confuso sobre lo que en verdad quería decir" (Apología, 21b). No se trata de un ejercicio de interpretación, un esfuerzo de exégesis de aquello que el dios habría dicho de modo alegórico -medio verídico y medio engañoso-, sino más bien de una indagación dirigida a establecer si el oráculo ha dicho la verdad: "Sócrates quiere probar lo dicho por el oráculo. Se propone someterlo a una verificación”. O en palabras más claras: "Sócrates, por lo tanto, no va a interpretar el oráculo sino a discutirlo, a someterlo a discusión, a oposición, para saber si es verdadero" (Foucault, 2010, p. 97). Y el modo de hacerlo consiste en hacer reproches, objeciones, cuestionamientos, interrogatorios, oponiéndose a alguien para saber si lo dicho se sostiene sólidamente.

A diferencia de Querefonte, quien cree en la profecía y la palabra oracular sin ninguna vacilación, Sócrates pone en entredicho al oráculo en aras de comprobar su verdad. Por supuesto, esta posición respecto al saber-poder divino es completamente diferente, ya que discute y refuta la verdad de lo sagrado, la palabra del oráculo, con el fin de establecer si podrá aceptársela como un logos 
verdadero (Foucault, 2010, p. 98). Ahora, Foucault avanza en la cuestión preguntando: ¿cuál es la forma de veridicción socrática respecto al oráculo? $\mathrm{O}$, en otros términos, ¿cómo sabrá, en efecto, si la palabra del oráculo es verdadera? He aquí el segundo momento: la indagación recorre no solo el enigmático cuerpo del saber divino, sino también, y más puntualmente, la ciudad y el cuerpo total de sus ciudadanos, a partir de sus diferencias sociales y políticas. En principio, Sócrates distingue los saberes del hombre de Estado, el poeta y el artesano, para concluir que, pese a sus diferentes saberes, o mejor aún, a sus distintas posiciones frente al saber caracterizadas por el hecho de creer conocer las cosas, en realidad no saben nada en absoluto. Sócrates, en cambio, sabe que no sabe. Aquí reside justamente el progreso en la indagación por la verdad, esto es, en el juicio, el cuestionamiento, el examen de los otros en comparación consigo mismo, que recibe el nombre de exétasis. Exetazein es someterse a examen. En el caso de Sócrates, esta indagación se realiza a través de tres maneras, a saber: en primer lugar, comprobando si el oráculo ha dicho la verdad. En segundo lugar, poniendo las almas a prueba sobre aquello que saben y no saben acerca de las cosas: su oficio, su actividad, y, sobre todo, acerca de sí mismas, esto es, sobre aquello que saben y no saben de sí. Finalmente, en tercer lugar, confrontando las almas de los otros con la de Sócrates.

Esta forma de decir veraz o de veridicción origina una cierta forma de parresía, si se entiende por tal el coraje de la verdad, el coraje de decir la verdad (Foucault, 2010, p. 99). O en palabras más breves, la voz socrática inaugura la práctica de la filosofía que, sin lugar a dudas, constituye otra forma de decir la verdad. En efecto, el pensador francés es enfático en afirmar que la parresía filosófica es distinta a la parresía política, por cuanto representa la misión que el filósofo ateniense no abandonará jamás, incluso, ante el peligro inminente de la muerte. A diferencia del sabio que interviene en momentos precisos y, amo en su sabiduría, se mantiene silencioso en su retiro, Sócrates tiene una responsabilidad permanente con la verdad, permaneciendo en su puesto como un soldado que lucha a cada instante por la defensa de sí y de los otros. Con admirable exactitud y belleza, Foucault (2010, p. 101) señala, justamente, que la misión socrática consiste en velar constantemente por los otros para que se ocupen de sí mismos, es decir, de su razón, de la verdad y de su alma (Nehamas, 2005, p. 57). Como bien lo dice el pensador francés, el ocuparse de sí constituye la definición capital de las ideas socráticas: "[e]l uno mismo en la relación de sí consigo, el uno mismo en esa relación de vela 
sobre sí mismo" (Foucault, 2010, p. 101), la cual recibe el nombre de phrónesis, esto es, "la razón práctica, la razón en ejercicio, una razón que permite tomar las buenas decisiones y desechar las opiniones falsas" (Foucault, 2010, p. 101). Ahora, el término phrónesis se asocia a la noción de alétheia, puesto que las decisiones adecuadas conservan cierta relación que se funda ontológicamente en la naturaleza del alma. En otras palabras, la tarea socrática consiste en hacer que cada uno se ocupe de sí mismo en cuanto ser racional que tiene una relación con la verdad fundada en el ser de su propia alma (Foucault, 2010, p. 102).

Esta perspectiva alude a una parresía centrada en el eje de la ética: "[1]a fundación del éthos como principio a partir del cual la conducta podrá definirse como conducta racional en función del ser mismo del alma es, en efecto, el punto central de esa nueva forma de parresía" (Foucault, 2010, p. 102). La parresía socrática se caracteriza, pues, por el examen de aquello que dice la palabra del dios (zétesis), la prueba de las almas, unas respecto a las otras (exétasis); finalmente, el cuidado de sí que constituye, a su vez, el cuidado del otro (epimeleia) (Foucault, 2010, p. 101). En este punto, Foucault quiere mostrar, justamente, la diferencia entre la veridicción fundada en la política y la veridicción propia de la ética, toda vez que la primera alude exactamente a decir la verdad -con exclusión del examen de sí en relación con los otros- ante una asamblea o un tirano que no quiere escucharlo. De este modo, la parresía política se dirige a los otros para decirles qué deben hacer, omitiendo el decir orientado hacia el cuidado de sí mismo (epimeleia) y, una vez concluida su tarea, el parresiasta se retira a su soledad. Naturalmente, una y otra práctica son igualmente peligrosas, y por tanto, exigen de un gran coraje, aunque distinto, de decir la verdad.

En el caso de Sócrates, por ejemplo, el coraje en el decir veraz se manifiesta de dos maneras, a saber: primero, diciendo a los otros verdades que no son placenteras, incitándolos a encontrar la verdad de sí y, sobre todo, a actuar conforme a ella (Foucault, 2010, p. 105; Nehamas, 2005, p. 259). Al decir de Foucault, Sócrates muestra en su ignorancia a lo largo de la Apología "que lo que hace no consiste, como en el caso de un profesor, en transmitir a los que saben, tranquilamente y sin correr riesgos, lo que él mismo sabe, pretende saber o cree saber". E inmediatamente agrega: "[a]l contrario, lo que él hace es mostrar valerosamente a los otros que no saben y que deben ocuparse de sí mismos" (Foucault, 2010, p. 105). Para el pensador francés, el coraje constituye el eje central de su imagen sobre 
Sócrates, quien lo ejerce permanentemente sobre su propia alma y las de los otros. A diferencia del profesor que dice "yo sé, ustedes escúchenme", Sócrates dice "yo no he sido jamás maestro de nadie, yo no sé nada, y si me ocupo de ustedes no es para transmitirles el saber que les falta, es para que, al comprender que no saben nada, aprendan con ello a ocuparse de ustedes mismos" (Apología, 21b; Foucault, 2010, p. 105). El coraje en el decir veraz se manifiesta, en segundo lugar, siendo útil a la ciudad, a sus conciudadanos y a sus amigos, es decir, incitándolos a cuidarse a sí mismos por medio del uso de la razón, del decir veraz y de la prueba de su alma (phrónesis, alétheia y psykhé). Según Nehamas, Foucault se espeja en Sócrates ya que su escritura (su obra) constituye, asimismo, una apología del arte de vivir, del ejercicio artístico de esculpirse a sí mismo, estimulando para sí y para otros nuevas posibilidades de creación. Al igual que Sócrates, el escritor francés forjó su pensamiento en virtud del decir veraz y, especialmente, a favor de los excluidos y los oprimidos de la historia, quienes no han logrado hablar con su propia voz. Así las cosas, Nehamas (2005) advierte:

[Foucault] emprendió su proyecto, el cuidado de su propio yo, para desarrollar una voz de la que otros como él se pudieran adueñar en sus mismos términos, y a través de la cual cuidar de sí mismos en la manera que su propio yo y circunstancias lo requieran. Escribió que, después de todo, estaba tratando de desarrollar un modo de trabajar sobre nosotros mismos que nos pudiera permitir inventar - no quiero decir- un modo de vivir que aún es improbable (p. 260).

Retomando la lectura de Foucault sobre Sócrates, resulta claro entonces que el cuidado de sí, a partir del decir y el hacer veraz, la propia vida, constituye el elemento central del ciclo de la muerte socrática. Este factor será fundamental, a su vez, para comprender el último decir veraz de Sócrates: "Critón, debemos un gallo a Asclepio. Así que págaselo y no lo olvides” (Fedón, 118a).

\section{Sócrates y los peligros del olvido de sí}

NO OLVIDAR, NI DESCUIDAR; recordar. ¿Qué significan las últimas palabras socráticas, tan inquietantes como conmovedoras? Foucault (2010, pp. 110-111) tiene que vérselas con distintas interpretaciones que coinciden -desde hace casi dos mil años- en afirmar que Sócrates concibe la vida como una enfermedad y la 
muerte como su curación. Olimpiodoro (495-570 d. C) advierte, por ejemplo, que la ofrenda del gallo a favor de Asclepio debe entenderse como la curación que recibe el alma debido a los sufrimientos causados por el devenir. Así las cosas, la muerte es la vía de acceso a la eternidad, escapando al tiempo, sus cambios y sus corrupciones. Y, en el mismo sentido, Nietzsche (2014) expresa en La gaya ciencia, aforismo 340: “'Oh, Critón, debo un gallo a Esculapio. Estas ridículas y últimas palabras significan, para quien sepa escucharlas: 'Oh, Critón, la vida es una enfermedad”' (p. 856). Ahora, el filósofo alemán señala seguidamente la contradicción entre la vida del filósofo ateniense, sus palabras y sus hechos, y su agonía en que desmentía su actitud ante la existencia:

El Sócrates moribundo. -Admiro la valentía y la sabiduría de Sócrates en todo lo que hizo, dijo y no dijo. Este ateniense burlón y enamorado, espíritu maligno y cazador de ratas que hacía temblar y sollozar a los jóvenes más arrogantes, no era solo el parlanchín más sabio que ha habido: era igualmente grande en callar. Quisiera que hubiera estado callado también en el último instante de la vida -quizá pertenecería entonces a un orden de espíritus aún superior-. Ya fuera la muerte, el veneno, la piedad o la maldad, algo le soltó en ese instante la lengua y dijo: "Oh, Critón, le debo un gallo a Asclepio". Esta ridícula y última palabra quiere decir, para quien tenga oídos: "Oh, Critón, la vida es una enfermedad". ¡Es posible! Un hombre como él, que vivió alegremente y, a los ojos de todos como un soldado, jera pesimista! ¡Sólo le había puesto buena cara a la vida y había ocultado durante toda ella su juicio último, su sentimiento más íntimo! ¡Sócrates, Sócrates ha sufrido por la vida! ¡Y aun ha tomado su venganza por ello, con esa palabra velada, terrorífica, piadosa, blasfema! ¿Un Sócrates también tenía que vengarse? ¿Faltaba un grado de magnanimidad en su riquísima virtud? ¡Ay amigos! ¡Tenemos que superar también a los griegos! (Nietzsche, 2014, \$340, pp. 856-857).

Sin embargo, Foucault indica que la interpretación nietzscheana sobre las últimas palabras de Sócrates resulta insostenible, ora por el sentido de la obra platónica en relación con la vida buena, ora por el significado del ciclo de la muerte socrática acerca de la vida exenta de las falsas opiniones, esto es, confiada a la verdad y la justica: "Que la vida no es una enfermedad, que la vida no es un mal en sí misma, se dice con claridad” (Foucault, 2010, p. 114). En palabras del pensador francés, el pensamiento socrático revela de punta a punta una vida auténticamente filosófica, una vida pura, una vida imperturbable, sin ninguna 
pasión, deseo, apetito desenfrenado, ni falsa opinión. Y, justamente, la pureza de la vida se obtiene mediante la atención positiva de la divinidad, tal y como lo testifica el mismo Sócrates al concebir la existencia como una experiencia del cuidado en sus distintas modalidades. Así se corrige la canónica interpretación nietzscheana, a saber: el cuidado de los dioses con los hombres, de los padres hacia sus hijos, del pastor con su rebaño, de un buen soberano con los ciudadanos de su país. De ahí que no haya que suicidarse, puesto que siempre existen otros que cuidan de los demás (Foucault, 2010, p. 115). De este modo, Foucault concluye que Sócrates, en modo alguno, se aparta de la vida, sino más bien del cuerpo, lo que entraña una diferencia sustancial:

[Sócrates] [n]o se aparta de la vida, se aparta, en esta, de su cuerpo, lo cual es desde luego algo muy diferente. Pero contempla, hasta el momento en que los dioses nos hagan una señal (es decir, hasta el momento de nuestra muerte), la posibilidad de vivir de ese modo, no contaminados y puros. Esa vida no contaminada y pura que es la de Sócrates, ¿cómo podría concebirse cual si fuera una enfermedad? (Foucault, 2010, p. 116).

Ahora, esa vida socrática, auténtica y pura, ¿cómo podría concebirse cual si fuera una enfermedad? El pensador francés insiste en que en la Apología los dioses amparan al filósofo ateniense, procurándole una vida buena. Por consiguiente, el sacrificio a favor del dios Asclepio no puede ser más que un agradecimiento por dicha atención. El sabio ha llevado una vida tan apartada del apetito del cuerpo que no puede haber para él más que dicha y ventura: "[e]n el momento en que va morir, en que acepta morir, en que está dichoso de morir, Sócrates jamás dice ni piensa, ni ha dicho ni pensado, que la vida es una enfermedad" (Foucault, 2010, p. 117). La contradicción es, pues, evidente: por un lado, el sacrificio a favor del dios Asclepio alude a un rito de curación: Asclepio=gallo=enfermedad, y, por otro lado, la muerte socrática, lejos de concebirse como una enfermedad, constituye una ocasión de encuentro para conversar con los sabios: vida $=$ muerte $=$ dicha . Acudiendo a Dumézil, Foucault despeja el enigmático contenido del último decir de Sócrates, afirmando que, en principio, la opinión de los otros, los muchos, no debe tomarse en cuenta porque genera la corrupción del alma. A decir verdad, "conviene 'no preocuparse' por la opinión de todo el mundo" (Foucault, 2010, p. 120). He aquí la relación fundamental: la relación de sí consigo, que exige de una sana orientación en relación con el saber de las cosas y de nosotros 
mismos, ora mediante el examen de todo lo existente, incluyendo el decir de los dioses, ora mediante la atención a los sabios. Hay que seguir la verdad, porque la misma evita el deterioro de sí en relación con el decir de la multitud, tan confuso como peligroso para el alma: "[1] as opiniones que no hayan sido examinadas, cotejadas, probadas en términos de verdad, corromperán, destruirán, deteriorarán y echarán a perder el alma" (Foucault, 2010, p. 120). Sócrates se refiere, pues, a la enfermedad del alma causada por la falsa opinión, la cual orienta de forma distorsionada la imagen del mundo, de los otros y de sí mismo, así como de las acciones.

La corrupción del alma se evita, en cambio, mediante la opinión racional, el logos racional -phrónesis-, llevando al alma de su estado de corrupción a un estado de salud. Critón, por ejemplo, en la discusión con Sócrates, se ha liberado de la opinión de todos, decidiéndose, al contrario, por una opinión verdadera fundada en la relación de sí mismo con la verdad. Por lo tanto, uno y otro deben agradecerle a Asclepio. Hasta aquí, Foucault (2010, pp. 122, 124) resume la postura dumeziliana sobre las últimas palabras de Sócrates referidas a Critón, incluyendo las comparaciones con las tragedias de Esquilo y Sófocles; sin embargo, apela además a una serie de textos contenidos en el Fedón, especialmente a las opiniones de Cebes y Simmias, que confirman la idea según la cual el rito de curación socrática alude estrictamente a la superación de las opiniones comúnmente admitidas sin ningún miramiento ni vacilación. Critón padecía de una enfermedad que le hacía pensar que para Sócrates era mejor vivir que morir; mientras que Cebes y Simmias sufrían la enfermedad que los inducía a creer que, si uno muere, no tiene la certeza de liberar un alma inmortal (Foucault, 2010, p. 124). Así que los discípulos de Sócrates padecían de un tipo de enfermedad cuya curación dependía del sacrificio de un gallo a favor de Asclepio. No obstante la aparente claridad, esto es, la enfermedad de Critón, Cebes y Simmias, Foucault (2010) pregunta nuevamente: “¿[p]or qué Sócrates dice: Critón, debemos un gallo a Asclepio?” (p. 124). O, en otras palabras, ¿̨por qué la apelación se dice en plural? Sócrates también se ha curado. Pero, ¿cuál es su enfermedad? Citando a Dumézil, Foucault señala que entre Sócrates y sus discípulos más cercanos hay un lazo de amistad tal que cuando uno de ellos padece la enfermedad los otros se conduelen de esta afección, por ello Sócrates participa de este sentimiento.

Además de la empatía frente a sus amigos, Sócrates reconoce su coraje ante sí mismo, ante los otros, ante los dioses y ante la verdad, evitando así incurrir en 
la seducción de la fuga propuesta por su amigo Critón. El filósofo no se ha olvidado de sí mismo, ni de su deber de cuidado ante sí y los otros. Y mientras no esté muerto, el coraje de la verdad persistirá en el filósofo ateniense. Por esta razón, el ritual de curación se hará en nombre de todos, incluyendo al maestro. Y este es el último gesto socrático de amistad y de coraje consigo mismo y con sus amigos. En palabras de Foucault (2010), la solidaridad constituye un elemento definitivo en la comprensión de la dramaturgia contenida en los diálogos platónicos: “[y] Sócrates tiene no pocas oportunidades de decirlo en otros diálogos: si triunfa el mal discurso, es una derrota para todos, pero si triunfa el buen discurso, todo el mundo gana" (p. 125). En efecto, el pensamiento socrático constituye un pacto implícito entre él y cualquiera de sus interlocutores. Tal pacto consistente en que el descubrimiento de la verdad prevalecerá para unos y otros, quienes habrán de reconocerla. De modo que todos han sido solidarios en ese ejercicio de la verdad y, por supuesto, en la operación curativa que ha evitado el contagio de todos; es por esto que todos deben agradecer a Asclepio. Ahora, la operación curativa no sugiere en algún modo un método médico o psiquiátrico, por cuanto la enfermedad no radica en una deficiencia mental, sino, más bien, en las prácticas propias de la epimeleia:

Ocuparse de alguien. Ocuparse de un rebaño, ocuparse de la familia o, como lo encontramos con frecuencia en lo concerniente a los médicos, ocuparse de un enfermo: eso es lo que se llama epimeleisthai. La curación de la que habla Sócrates aqui forma parte de todas esas actividades por las cuales uno se ocupa de alguien. Lo atiende si está enfermo, vigila su régimen para que no se enferme, le prescribe los alimentos que debe comer o los ejercicios que debe realizar, y las actividades, asimismo, por las cuales se le indican las acciones que debe hacer y las que debe evitar, por las cuales se lo ayuda a descubrir las opiniones verdaderas que hay que seguir y las opiniones falsas [de las que hay que prevenirse]; es [aquello] mediante lo cual se lo nutre de discursos veraces. Todo esto compete al epimeleisthai (Foucault, 2010, p. 126; énfasis añadido).

La epimeleia como cuidado de sí consigo y los otros puede adoptar así una tipología variada de casos, siendo la más urgente aquella referida a la falsa opinión que amenaza con el peligro de olvidarse de sí mismo, prestando demasiada atención a las opiniones de los muchos y los anónimos. El ciclo socrático está atravesado por la epimeleia, pero también por el peligro de olvidarse de sí mismo. 
Aquí residen las últimas palabras de Sócrates, o más bien su última voluntad: "ocupaos de vosotros mismos", esto es, de echarse de menos y retroceder ante el peligro del descuido; así como el agradecimiento al dios de la curación, quien alienta el cuidado de sí y de los otros. Las expresiones no olviden, no descuiden, recuerden, consisten, pues, en ocuparse de la propia vida, atendiendo a la verdad de sí mismo. No hay que descuidar el sacrificio a Asclepio o, en otras palabras, el cuidado de sí: "[n]o olviden hacer ese sacrificio al dios, ese dios que nos ayuda a curarnos cuando cuidamos de nosotros mismos" (Foucault, 2010, p. 129). La fórmula curación = cuidado es ejemplificada radicalmente por el mismo Sócrates, quien se empeñó en cuidar de los otros tal y como cuidó de sí mismo, con absoluto coraje. Y de este modo Foucault (2010) concluye su lectura sobre Sócrates:

Creo que la muerte de Sócrates funda en la realidad del pensamiento griego, y por ende en la historia occidental, la filosofía como una forma de veridicción que no es ni la de la profecía, ni la de la sabiduría, ni la de la tekhne; una forma de veridicción característica, precisamente, del discurso filosófico, y cuyo coraje debe ejercerse hasta la muerte como una prueba del alma que no puede tener su lugar en la tribuna política (p. 130).

\section{A modo de conclusión}

NO OLVIDARSE, NI DESCUIDARSE, SINO RECORDARSE, alude pues a una cierta manera de hablar, más precisamente, de decir la verdad sobre sí mismo. Y este decir constituye el vínculo del sí consigo y con el otro, quizá el más valeroso, en tanto implica decir la verdad con todos sus riesgos. En palabras de Foucault (2010), el libre coraje por el cual uno se liga a sí mismo en el acto de decir la verdad instituye la ética del decir veraz, arriesgado y libre, evitando así el autoolvido. En este punto, basta recordar las palabras de Dioniso a Ariadna como el mejor ejemplo de la oposición extravío/retorno del sí: "[s]é prudente, Ariadna, dijo Dioniso, tienes orejas pequeñas, tienes mis orejas: mete en ellas una palabras prudentes! ${ }_{-}$¿No hay que odiarse primero, cuando se debe amar? Yo soy tu laberinto (Nietzsche, 2016, p. 891). Ariadna, que en la lengua griega de Creta significa "extremadamente pura", ari-hagne, también llamada Aridela, es decir, "extremadamente brillante”, nieta de Helios y de Zeus, hija de Minos, decide traicionar al Minotauro por amor a Teseo, haciéndole prometer que la hará su esposa. El 
joven ateniense acepta la oferta y jura que se casará con ella. Seguidamente, Ariadna le entrega a Teseo un secreto: el ovillo mágico para entrar y salir del laberinto, advirtiéndole que nunca lo suelte de su mano. Debe abrir la puerta de entrada y atar el cabo del ovillo en lo alto del dintel; el ovillo irá girando y girando en disminución mientras Teseo avanza por tortuosos recodos y esquinas hasta llegar al recinto donde se aloja el Minotauro, el monstruo con cuerpo de hombre y cabeza de toro. En el lugar más recóndito duerme el monstruo, quien es muerto por Teseo en nombre de Poseidón. Unos días después, el joven ateniense embarca su nave con Ariadna, a la que abandona dormida.

Sin calcular, dudar o sospechar, Ariadna renuncia a toda seguridad, avanzando en el vacío, en lo desconocido. A diferencia de Teseo, que se une al hilo que la mujer sostiene firmemente para sujetarlo, ella se lanza sin hilo, sin ninguna ligadura a sí misma y, en cambio, a la espera de lo otro (Cixous, 1995, p. 31). Teseo se hace reconocer durante el tiempo de su descenso al laberinto, haciendo desaparecer a Ariadna, dejándole simplemente el beneficio de una promesa -o de una ganancia imaginaria-. Ariadna será quien aguante y resista durante todo el tiempo necesario para que él pueda experimentar el conocimiento de su fuerza y su deseo, a fin de darle a gozar, sin demasiados obstáculos, el retorno que él realiza a sí mismo, crecido -afianzado a sus propios ojos- (Cixous, 1995, pp. 38-39). Aquí cabe imaginar que la diferencia entre las partes del drama se erige como coincidencia negativa, lo que implica que el encuentro de uno suponga la negación del otro, ya que la negación envuelve así el máximo nivel de atadura en el que uno representa al otro como pasivo, y, por tanto, objetivable. Mientras uno asume el riesgo y la responsabilidad de ser una parte, un agente libre donde tienen lugar las transformaciones, el otro se repliega a la pasividad o a la espera del tiempo activo en el cual él explora el laberinto del conocimiento. Por esta razón, Teseo avanza en el laberinto con el hilo (astucia) y la espada (violencia) en una suerte de privilegio respecto a lo otro, a fin de conservar su poder y sus privilegios, mientras Ariadna se pierde en el olvido, el extrañamiento de sí misma, arriesgando su propia vida (Cixous, 1995, p. 37).

Como era de esperarse, el abandono de Teseo le ocasiona a Ariadna un gran sufrimiento. Sin embargo, la doncella experimenta el nacimiento de una nueva promesa de goce, de eternidad y de salvación cuando se encuentra con Dioniso, pues en él ve la imperativa necesidad de construir un sentido auténtico de la vida 
a partir del retorno a sí misma. El laberinto, la propia vida, otrora abandonado al servicio de otro, pasará a ser el lugar al que Ariadna regresa: el laberinto ya no es el del conocimiento del otro, sino el de la propia vida. Ariadna se convierte entonces en potencia afirmativa, lanzándose hacia el no saber como condición del descubrimiento. Y al igual que Dioniso, Sócrates exhorta a sus amigos a no olvidarse, sino, en cambio, a descubrir auténticamente el saber, llegando a ser quien se es. El olvido de sí es subvertido ahora por el descubrimiento de sí, la invención de sí mismo mediante el razonamiento claro y el decir veraz. Por ello, el enigma del laberinto resulta análogo al misterio de la vida, incluyendo el decir de los dioses, que exige, más allá de los artificios creados por la habilidad y la astucia del lenguaje, el valor ante la verdad de sí y de los otros. Dar vuelta al mundo inauténtico, a la impostura y a la servidumbre constituye, por tanto, la enseñanza de Sócrates, quien se esforzó en la búsqueda intensa del saber, la exaltación del buen vivir y el amor a sus amigos y a sus conciudadanos.

\section{Referencias}

Bollack, J. (1999). La muerte de Antígona. La tragedia de Creonte. (Trad. A. Pons y J. Riu). Madrid: Arena Libros.

Cirlot, J. (2014). Diccionario de simbolos. Buenos Aires: Grupal-Siruela.

Cixous, H. (1995). La risa de la medusa. Ensayos sobre la escritura. (Trad. M. Díaz-Diocaretz). Barcelona: Anthropos.

De Romilly, J. (2004). La ley en la Grecia clásica. (Trad. G. Potente). Buenos Aires: Biblos.

Dumézil, G. (1989). Nostradamus. Sócrates. (Trad. J. Almela). México D. F.: Fondo de Cultura Económica.

Esquilo. (2006). Agamenón. En Tragedias. (Trad. B. Perea). Madrid: Gredos.

Homero. (2007). Odisea. (Trad. L. Segala y Estalella). Madrid: Austral.

Foucault, M. (2009). El gobierno de síy los de los otros. Curso en el Collège de France (1982-1983). (Trad. H. Pons). Buenos Aires: Fondo de Cultura Económica. 
Foucault, M. (2010). El gobierno de sí y los de los otros II. Curso en el Collège de France (1983-1984). (Trad. H. Pons). Buenos Aires: Fondo de Cultura Económica.

Nehamas, A. (2005). El arte de vivir. Reflexiones socráticas de Platón a Foucault. (Trad. J. Brioso). Valencia: Pre-Textos.

Nietzsche, F. (2014). La gaya ciencia. (Trad. J. Aspiunza, M. Parmeggiani, D. Sánchez y J. Vermal). En Obras completas (Vol. III. Obras de madurez I). Madrid: Tecnos.

Nietzsche, F. (2016). Ditirambos de Dioniso. (Trad. M. Barrios, J. Bautista, J. Aspiunza, K. Lavernia, A. Martín y D. Sánchez). En Obras completas (Vol. IV. Escritos de madurez II y Complementos a la edición). Madrid: Tecnos.

Nussbaum, M. (2004). La fragilidad del bien. Fortuna y ética en la tragedia y la filosofía griega. (Trad. A. Ballesteros). Madrid: La balsa de la medusa.

Platón. (2011). Apología. (Trad. J. Calonge). En Diálogos (Vol. I). Madrid: Gredos.

Platón. (2011). Critón. (Trad. J. Calonge). En Diálogos (Vol. I). Madrid: Gredos. Platón. (2011). Fedón. (Trad. J. Calonge). En Diálogos (Vol. I). Madrid: Gredos. Sófocles. (2000). Antígona. (Trad. J. Bergua). En Sófocles. Ayax, Antígona, Edipo Rey, Electra, Edipo en Colono. Madrid: Gredos. 